\title{
Model effects on GLAS-based regional estimates of forest biomass and carbon
}

\author{
ROSS NELSON* \\ Code 614.4, Biospheric Sciences Branch, NASA Goddard Space Flight Center, Greenbelt, \\ Maryland 20771, USA
}

\begin{abstract}
Ice, Cloud, and land Elevation Satellite (ICESat) / Geosciences Laser Altimeter System (GLAS) waveform data are used to estimate biomass and carbon on a 1.27 $\times 10^{6} \mathrm{~km}^{2}$ study area in the Province of Québec, Canada, below the tree line. The same input datasets and sampling design are used in conjunction with four different predictive models to estimate total aboveground dry forest biomass and forest carbon. The four models include non-stratified and stratified versions of a multiple linear model where either biomass or (biomass) ${ }^{0.5}$ serves as the dependent variable. The use of different models in Québec introduces differences in Provincial dry biomass estimates of up to $0.35 \mathrm{G}$, with a range of $4.94 \pm 0.28 \mathrm{Gt}$ to $5.29 \pm 0.36 \mathrm{Gt}$. The differences among model estimates are statistically non-significant, however, and the results demonstrate the degree to which carbon estimates vary strictly as a function of the model used to estimate regional biomass. Results also indicate that GLAS measurements become problematic with respect to height and biomass retrievals in the boreal forest when biomass values fall below $20 \mathrm{tha}^{-1}$ and when GLAS 75th percentile heights fall below $7 \mathrm{~m}$.
\end{abstract}

\section{Introduction}

The forestry Light Detection and Ranging LiDAR community, having demonstrated the utility of airborne LiDAR systems for forest measurement and monitoring, must now consider doing so from space. One civilian space LiDAR, the Ice, Cloud, and land Elevation Satellite (ICESat) carrying the Geosciences Laser Altimeter System (GLAS) LiDAR, is currently in orbit. The US may launch three additional space LiDAR systems over the next decade. This article briefly describes these proposed space LiDARs, the configurations of which are all under discussion and subject to change. We also introduce two concerns associated with space and airborne LiDAR instruments that must be addressed by our community if we hope effectively to monitor global forest resources with lasers. In order to monitor forest change at the regional, national, continental, or global scale, our estimates at time $1(t 1)$ and time 2 ( $t 2)$ must be consistent. Spurious changes may be noted or actual changes may be missed if our $t 1$ and $t 2$ estimates are not comparable. Assuming the use of the same sampling design, inconsistencies may be introduced by the use of different predictive models at $t 1$ and $t 2$ and/or they may be introduced by sensor changes over time, which might result in systematic measurement differences. The primary objective of this paper is to address the former, i.e. model consistency, providing one example of the degree to which the use of different predictive models impacts upon regional estimates of biomass and carbon made using space LiDAR measurements. A secondary

*Email: Ross.F.Nelson@nasa.gov 
objective is to report possible measurement limitations of the current space LiDAR, ICESat / GLAS, with respect to measuring forest height and biomass.

\subsection{US space LiDARs - current thoughts on future missions}

The US National Research Council (NRC), in a document known as the Decadal Survey (National Research Council 2007), has identified 17 space missions of paramount importance to the US scientific community for monitoring the status and function of the biosphere. The NRC suggests that these 17 missions be launched in the 2010-2020 time frame. Three of these Earth remote-sensing missions incorporate space LiDARs capable of measuring forest structure. These missions include: (1) ICESat II, a follow-on to the current ICESat satellite (Abshire et al. 2005), designed to monitor ice-sheet elevation changes; (2) Deformation, Ecosystem Structure, and Dynamics of Ice (DESDynI), primarily a solid Earth mission that couples an L-band radar and LiDAR to map surface deformation; and (3) Laser Imaging for Surface Topography (LIST), a swath mapping LiDAR for global topography and hydrology. All will be in near-polar orbits.

The specific designs of ICESat II and DESDynI are currently topics of much discussion, so the descriptions below may not resemble the configurations that ultimately reach orbit. In addition, the launch of these three satellites is by no means assured, given the prerequisite that the US Congress must find the funds needed to build and operate this hardware. However, the Decadal Survey carries much weight at NASA, and the current expectation is that ICESat II will be launched somewhere in the 2016-2018 time frame in a flight configuration markedly different from ICESat I. ICESat I was a single beam, near-infrared $(1.064 \mu \mathrm{m}), 40 \mathrm{~Hz}$ waveform profiler with 50-70 $\mathrm{m}$ footprints and an along-track post-spacing of $172 \mathrm{~m}$. The current design for ICESat II calls for the use of a multi-beam, $10 \mathrm{kHz}$ micropulse LiDAR system that will collect ranging data from individual green $(0.532 \mu \mathrm{m})$ photons every $70 \mathrm{~cm}$ along-track. The 2016-2018 launch window is notable in that the third and final laser on ICESat I failed on 19 October 2008. The second of three lasers, which previously had dropped below acceptable power levels, was subsequently brought back online to acquire lowpower ranging observations over ice, but the laser power available makes the utility of these measurements questionable for vegetation assessment. Thus we can expect an ICESat I 1/N ICESat II observational hole of $\sim 9$ years.

The DESDynI and LIST missions will fly later, DESDynI perhaps in 2019. Expectations are that DESDynI will most likely be some sort of multi-beam waveform profiling LiDAR with $\sim 25 \mathrm{~m}$ footprints and a $25-30 \mathrm{~m}$ post spacing, i.e., nearcontiguous profiles along-track. Each of the five parallel profiles may be separated from adjacent, simultaneously acquired profiles by approximately $850 \mathrm{~m}$, thus the left- and rightmost outer beams will be $3.4 \mathrm{~km}$ apart across-track, assuming a mission design life of five years. If, due to budget concerns, the DESDynI LiDAR is designed to operate for 3 years, the distance between adjacent beams may be $940 \mathrm{~m}$, leading to an across-track swath dimension of $\sim 3.8 \mathrm{~km}$. The DESDynI mission is currently configured as two free-flying satellites, one an L-band radar and the second a multibeam LiDAR. Many aspects of this joint radar-LiDAR mission are being discussed, including orbital repeat times, orbital baseline issues regarding the radar acquisitions, the radar acquisition capabilities, e.g. Synthetic Aperture Radar (SAR) versus Interferometric SAR (InSAR), LiDAR beam spacing, number of beams, off-nadir 
pointing capabilities and pulse width. ${ }^{*}$ LIST is currently configured as a swath mapper, collecting global wall-to-wall coverage over its 5 year design life. The footprint of the contiguous pulses will be of the order of $5 \mathrm{~m}$, as will the post spacing of adjacent footprints both along- and across-track. Given LIST's late launch, most effort is going into research to address the ICESat II and DESDynI flight configurations.

\subsection{Using ICESat I GLAS to measure forests}

In the context of the current ICESat profiler and the possibility of an ICESat II follow-on, the forestry LiDAR community may, in about 6 years, enter a period where space-based LiDAR measurements are routinely collected globally and systematically. With this capability comes questions concerning how we might best use these satellite ranging observations to measure, and more importantly, monitor forest biomass and carbon resources at regional, national, continental and global scales.

Although the ICESat / GLAS LiDAR is not optimally configured for or operated as a vegetation assessment tool, these data have proved useful for biomass and carbon assessments across areas spanning hundreds of thousands of square kilometres. Nelson et al. (2009a) and Boudreau et al. (2008) report results of studies that employ the ICESat / GLAS LiDAR to estimate forest volume, biomass and carbon in south central Siberia (just north of Mongolia) and in Québec, Canada, respectively. Nelson et al. (2009a) used 101831 GLAS waveforms acquired along 55 orbits over a $10^{\circ} \times 12^{\circ}, 811$ $414 \mathrm{~km}^{2}$ area just northwest of Lake Baikal to attribute 16 forest-cover type-canopy density classes derived from Moderate Resolution Imaging Spectrometer (MODIS) data. Using field observations acquired on 51 GLAS pulses, they developed a sparse neural network relating GLAS waveform metrics to ground estimates of merchantable volume (Ranson et al. 2007). If they constrain their data and use only those pulses acquired on slopes of $10^{\circ}$ or less as characterized using Shuttle Radar Topography Mission (SRTM) topographic information, their regional estimate of merchantable volume, $73.85 \times 10^{6} \pm 5.33 \times 10^{6} \mathrm{~m}^{3}$ (1 standard error), is within $1.1 \%$ of comparable ground estimates, $74.63 \times 10^{6} \mathrm{~m}^{3}$ (Shepashenko et al. (1998), per hectare estimate in conjunction with a percent forest-cover estimate of $63 \%$ from a 1990 Russian forest map, Grasia (1990)). If GLAS pulses on all slopes are considered, the regional GLASbased per hectare estimate of volume increases from $163.4 \pm 11.8 \mathrm{~m}^{3} \mathrm{ha}^{-1}$ to $171.9 \pm$ $12.4 \mathrm{~m}^{3} \mathrm{ha}^{-1}$, a $5.2 \%$ increase. This apparent increase in area-based volume estimates suggests that steeper slopes broaden the waveform response, increasing apparent canopy height and inflating the volume estimates. Slopes, as noted by Lefsky et al. $(2005,2007)$ and Rosette et al. (2008), negatively affect the height accuracy of the largefootprint GLAS waveform data, convolving forest-canopy architecture with topography, and increasing the vertical extent of the waveform. The tangent of the actual topographic slope multiplied by the GLAS footprint diameter provides an upper limit to the vertical pulse broadening expected due to slope (Lefsky et al. 2007; A. Neuenschwander, personal communication, 24 February 2009).

Boudreau et al. (2008) uses a multi-phase sampling approach to relate GLAS waveform and SRTM topographic measurements to field estimates of total above-ground dry biomass in Québec, Canada. They flew an airborne profiling LiDAR (the Portable Airborne Laser System (PALS); Nelson et al. (2003)) over existing ground plots and along GLAS orbital transects and developed two sets of equations. The first set relates

*This paragraph was updated at proof stage. 
field biomass estimates to airborne LiDAR metrics; the second set relates airborne LiDAR estimates of biomass to GLAS waveform metrics. They estimate that, on average, the forested areas of Québec that are south of the tree line support $38.9 \pm 2.2$ $\mathrm{t} \mathrm{ha}^{-1}$ of dry biomass. Botkin and Simpson (1990) report an average value of $41.8 \pm 10.1$ $\mathrm{t} \mathrm{ha}^{-1}$ for all of the North American boreal forest based on stratified ground measurements.

These studies report the accuracy and precision of statistical approaches that may be used to conduct regional inventories using a space LiDAR. Of interest in this paper, however is an assessment of the need for consistency in model selection when estimating regional biomass repeatedly over time. The objective of this study is to quantify the degree to which model differences may affect regional estimates of biomass and carbon. Four different models are used to estimate standing dry biomass and carbon for all of Québec below the tree line, an area encompassing $1.27 \times 10^{6} \mathrm{~km}^{2}$. In addition, results from the four models are compared to ground reference data to determine which of the four most closely estimates biomass in the southern half of the Province.

\section{Methods}

The datasets and analysis procedures employed in this study are the same as those described in detail in Boudreau et al. (2008). This study incorporates the following datasets:

1. ICESat / GLAS LiDAR waveform data. In the autumn of 2003, 104044 GLAS waveforms were acquired along 97 orbits across all of Québec, acquisition L2a. The spacing between adjacent near-N-S orbits are very variable but average $15.6 \mathrm{~km}$.

2. Digital vegetation zone map of Québec (MRNFPQ 2003). An ecozone map tessellates Québec into seven vegetation zones from south to north: (2.1) northern temperate forest, (2.2) mixedwood forest, (2.3) southern boreal forest (commercial forest), (2.4) northern Boreal forest (non-commercial forest), (2.5) taiga, (2.6) treed tundra, (2.7) Southern Arctic. The Southern Arctic vegetation zone, whose southern border is identified as the Provincial tree line, is assumed to contain no forest biomass.

3. Landsat Enhanced Thematic Mapper Plus (ETM+) land-cover map (Wulder et al. (2003); GeoTiffs available online at http://eosd.cfs.nrcan.gc.ca). Up to 24 land-cover classes are identified in each vegetation zone. Forests are identified as being conifer, hardwood or mixedwood, and each cover type is broken into three canopy density classes. The classified Landsat data are resampled to a $25 \mathrm{~m}$ grid.

4. SRTM digital elevation data. The SRTM radar data are available up to $60^{\circ} \mathrm{N}$ latitude. In Québec, the Provincial tree line tracks around $58^{\circ}-59^{\circ}$ N. A $3 \times 3$ window of $90 \mathrm{~m} \mathrm{SRTM}$ pixels around each GLAS pulse is used to characterize local topography.

5. Ministry of Natural Resources Québec (MNRQ) ground plots. The Ministry divides the Province into commercial and non-commercial forestland along an E-W line that roughly bisects the boreal zone, separating the three southern vegetation zones, 2.1, 2.2 and 2.3 (above), from the smaller-stature, more open forest to the north (Boudewyn et al. 2007). In the three southern zones, they measured 16814 , fixed area, $11.3 \mathrm{~m}$ radius, $400 \mathrm{~m}^{2}$, temporary sample plots between 1998 and 2004. Total above-ground dry biomass is calculated on each plot using equations available in Lambert et al. (2005). A small portion of these 
plots, ones more recently measured in 2000 to 2004, are used to develop the models reported below. All 16814 plots are used to validate the models.

6. Profiling airborne LiDAR data. The profiling data are used to tie ground-plot information to GLAS measurements. The PALS was flown over $\sim 5000 \mathrm{~km}$ of GLAS orbits and over 295 MNRQ ground plots during the summer of 2005. Of the 295 plots, 207 were actually intercepted by the airborne LiDAR's ground track. The near-infrared (NIR) profiler acquired sequential first/last returns on $0.40 \mathrm{~m}$ footprints at $0.12 \mathrm{~m}$ post spacing across ground plots and GLAS pulses.

These six datasets are used within a multi-phase sampling framework. Ground estimates of biomass were regressed against the airborne profiler measurements in order to develop predictive regressions based on the airborne measurements. One non-stratified equation (coefficient of determination, $R^{2}=0.65$ ) and a set of seven stratified ground-air equations $\left(R^{2}\right.$ values range from $0.51-0.73$, see table 2 in Boudreau et al. (2008)) are developed based on the Landsat land-cover strata. The ground-air equation(s) is (are) then used to calculate airborne laser-based estimates of biomass on 1325 GLAS pulses measured by the airborne profiler.

Four different models are constructed (number of observations, $n=1325$ ) to predict dry biomass as a function of GLAS waveform and SRTM topographic measurements. The four models follow:

- linear, non-stratified:

$$
\begin{aligned}
b_{\mathrm{air}, \mathrm{ns}}=-4.52+3.85 w_{\mathrm{GLAS}}-6.59 f_{\mathrm{GLAS}}-0.75 r_{\mathrm{SRTM}}, \\
R^{2}=0.60, \mathrm{RMSE}=32.0 \mathrm{tha}^{-1}
\end{aligned}
$$

- linear, stratified:

$$
\begin{aligned}
b_{\mathrm{air}, \mathrm{st}}=-2.37+3.63 w_{\mathrm{GLAS}}-5.92 f_{\mathrm{GLAS}}-0.73 r_{\mathrm{SRTM}}, \\
R^{2}=0.58, \mathrm{RMSE}=31.7 \mathrm{tha}^{-1}
\end{aligned}
$$

- square-root, non-stratified:

$$
\begin{aligned}
\sqrt{b_{\mathrm{air}, \mathrm{ns}}}= & 2.67+0.27 w_{\mathrm{GLAS}}-0.83 f_{\mathrm{GLAS}}-0.06 r_{\mathrm{SRTM}}, \\
& R^{2}=0.59, \mathrm{RMSE}=2.40 \sqrt{\mathrm{tha}^{-1}}
\end{aligned}
$$

- square-root, stratified:

$$
\begin{aligned}
\sqrt{b_{\mathrm{air}, \mathrm{st}}}= & 2.98+0.26 w_{\mathrm{GLAS}}-0.65 f_{\mathrm{GLAS}}-0.06 r_{\mathrm{SRTM}}, \\
& R^{2}=0.53, \mathrm{RMSE}=2.55 \sqrt{\mathrm{tha}^{-1}}
\end{aligned}
$$

where $b_{\text {air, ns }}$ is an airborne profiling estimate of biomass calculated using the nonstratified ground-air equation; $b_{\text {air,st }}$ is an airborne profiling estimate of biomass calculated using the stratified ground-air equations; $w_{\text {GLAs }}$ is the vertical extent of the GLAS waveform, signal start to signal end; $f_{\text {GLAS }}$ is the slope of the leading edge of the GLAS waveform; $r_{\mathrm{SRTM}}$ is the range (in metres) of the topographic difference found in a $3 \times 3$ pixel SRTM window centred on a GLAS pulse; and RMSE is the root mean square error.

The variance inflation factors for all four models are less than 1.61; multicollinearity is not an issue (Myers 1989). The square-root transform is used in an attempt to control marked heteroscedasticity; the transform only marginally 
improved residual patterns. The square-root biomass values are back-transformed using the unbiased back-transformation technique reported by Gregoire et al. (2008).

In the context of this study, stratification refers to the development of equations, by cover type and vegetation zone, in the ground-air phase, not in the air-satellite phase. In other words, the $b_{\text {air }}$ dependent variables in equations (2) and (4) above were calculated using stratified ground-air equations; the $b_{\text {air }}$ in equations (1) and (3) were calculated using a generic or non-stratified ground-air equation (table 2 in Boudreau et al. (2008)). Attempts were made to develop stratified GLAS equations for the linear and square-root models, but $R^{2}$ decreased significantly as the latitude of the vegetation zones increased and as the average height of the trees decreased. Stratified GLAS equations in the taiga and the treed tundra had $R^{2}$ values in the $0.1-0.2$ range, and were deemed unusable. This finding is not unexpected given the ground height-GLAS height comparisons reported in the literature. Sun et al. (2008) compare various GLAS height metrics to coincident airborne LiDAR estimates and report RMSEs of 3-5.5 $\mathrm{m}$ (their table 2) in the temperate forests of the eastern US. Rosette et al. (2008) report ground-GLAS height RMSEs of $2.86 \mathrm{~m}$ after correcting for topography. Lefsky et al. (2005) report RMSEs associated with ground-GLAS maximum canopy-height comparisons of $\sim 4.5 \mathrm{~m}$, and Lefsky et al. (2007), after correcting for local topography using trailing-edge measures, illustrate an RMSE of $5 \mathrm{~m}$ across diverse study sites in their figure 3. Given this height scatter and the open, sparse, stunted, coniferous nature of Québec's northern forests near the tree line, one might conclude that GLAS does not have the measurement sensitivity to accurately measure high-latitude forests. As a result, stratified GLAS equations were not employed in this study due to the lack of the predictive power of some of the northern equations. The stratified models, i.e. equations (2) and (4) above, were processed differently from the non-stratified models 1 and 3. Every GLAS shot was assigned to one of the Landsat land-cover classes based on the plurality of the land-cover types in a $3 \times 3$ Landsat ETM window that surrounded a given GLAS pulse. The nonstratified models were applied to all 104044 GLAS shots collected over Québec regardless of the land-cover identity of that GLAS pulse. So, GLAS pulses judged (by the Landsat classification) to have illuminated barren areas, rock, moss, herb, and so on, could still contribute to Provincial biomass if non-zero heights were measured by GLAS. In effect, in the non-stratified models, GLAS measurements superseded Landsat land-cover identities, and a GLAS pulse could contribute to the biomass estimate, even if the Landsat classification suggested that no forest biomass should exist on that spot illuminated by the GLAS pulse. Just the opposite was true with respect to the stratified models. Models 2 and 4 were used only on those GLAS shots judged to be capable of supporting forest biomass. In the case of the stratified models, then, specific cover types could never contain forest biomass, regardless of what the GLAS pulses intercepting that cover type may have measured. The net result of this processing rule is that the non-stratified models have higher biomass totals for the Province because they accumulate estimates across larger areas.

The lack of sensitivity in short-stature forests, noted above, calls into question the accuracy of the GLAS-based biomass and carbon estimates near the tree line. In order to better characterize this apparent phenomenon, the training dataset used to develop the airborne LiDAR-GLAS regressions was employed to assess the strength of two models as a function of latitude. The 6226 quality-assessed GLAS pulses overflown with the airborne profiler were subdivided into $131^{\circ}$ subsamples, i.e. $45^{\circ} \mathrm{N}$, which included all observations between $45.0^{\circ}-45.99^{\circ} \mathrm{N}, 46.0^{\circ} \mathrm{N}, 47^{\circ} \mathrm{N}, \ldots$, up to $57^{\circ} \mathrm{N}$. The 
14th latitude subsample included all airborne profiler-GLAS observations between $58.0^{\circ} \mathrm{N}$ and $60^{\circ} \mathrm{N}$ in order to avoid consideration of the $58^{\circ} \mathrm{N}$ latitude bin that contained only four samples. Only non-saturated GLAS pulses acquired on terrestrial (non-water) surfaces with slopes $<10^{\circ}$ and airborne profiling heights $<50 \mathrm{~m}$ were considered. The strengths of two linear relationships as characterized by the $R^{2}$ value were tracked in each latitude subsample: (1) $h_{75}$, GLAS $=f\left(h_{70}\right.$, airborne LiDAR, where $h_{75}$, GLAS refers to the $75 \%$ height, i.e. the height where $75 \%$ of the energy lies between it and the signal end, and $h_{70}$, airborne LiDAR refers to the height below which $70 \%$ of pulse heights along a profile that intersects a given GLAS pulse lies and (2) the non-stratified linear biomass model, equation (1). The objective of this portion of the study was to determine if there were height or biomass limits below which GLAS proved to be relatively insensitive to forest structure.

\section{Results}

\subsection{Model effects on regional GLAS biomass and carbon estimates}

Table 1 reports per hectare and total biomass estimates for the entire $1.27 \times 10^{6} \mathrm{~km}^{2}$ Province of Québec south of the tree line. The models are ranked largest to smallest in terms of total Provincial biomass, and, as one would expect due to processing rules, the non-stratified models report the largest Provincial biomass totals.

The exact same data are input into each model to calculate model coefficients. Based on model differences alone, Provincial biomass and carbon estimates vary by approximately $7 \%$, even under the ideal circumstance that all of the data input into the various models are identical. No such ideal circumstance would exist if one were monitoring regional biomass over time, since the input data would certainly change between $t 1$ and $t 2$. The 7\% difference amounts to, in Québec, a model-induced difference of $0.35 \mathrm{Gt}$ of biomass, or $0.18 \mathrm{Gt}$ of carbon, assuming a conversion factor of $0.5 \mathrm{t} \mathrm{C}$ per $1 \mathrm{t}$ dry biomass (Gower et al. 1997, Houghton et al. 2000). None of the models are significantly different from any of the others at the $95 \%$ level of confidence. However, if these model-driven differences were added to differences induced by changing sensors or changing sampling frameworks, statistical insignificance might not be assured. Given a current carbon credit price of $\sim 15$ euros per ton of carbon, this scenario might result in an undeserved carbon penalty or an unearned

Table 1. Provincial estimates of total aboveground dry biomass on $1.27 \times 10^{6} \mathrm{~km}^{2}$ south of the tree line in Québec. Model estimates are ranked largest to smallest, top to bottom. All standard errors are calculated assuming simple random sampling, covariances are included, prediction errors are not. In the leftmost column, numbers in parentheses correspond to the models reported in $\S 2$.

\begin{tabular}{|c|c|c|c|c|c|}
\hline \multirow[b]{2}{*}{ Model } & \multicolumn{3}{|c|}{ Dry biomass estimates } & \multicolumn{2}{|c|}{ Provincial biomass totals } \\
\hline & $\begin{array}{l}\text { Mean } \\
\left(\mathrm{t} \mathrm{ha}^{-1}\right)\end{array}$ & $\begin{array}{c}\text { Standard } \\
\text { error }\left(\mathrm{t} \mathrm{ha}^{-1}\right)\end{array}$ & $\begin{array}{l}\text { Coefficient of } \\
\text { variation (\%) }\end{array}$ & Total (Gt) & $\begin{array}{l}\text { Standard } \\
\text { error }(\mathrm{Gt})\end{array}$ \\
\hline $\begin{array}{l}\text { Non-stratified, } \\
\text { Square-root (3) }\end{array}$ & 41.72 & 2.82 & 6.8 & 5.29 & 0.36 \\
\hline Non-stratified, Linear (1) & 40.63 & 5.21 & 12.8 & 5.15 & 0.66 \\
\hline Stratified, Linear (2) & 39.73 & 3.32 & 8.4 & 5.04 & 0.42 \\
\hline stratified, Square-root (4) & 38.94 & 2.17 & 5.6 & 4.94 & 0.28 \\
\hline
\end{tabular}




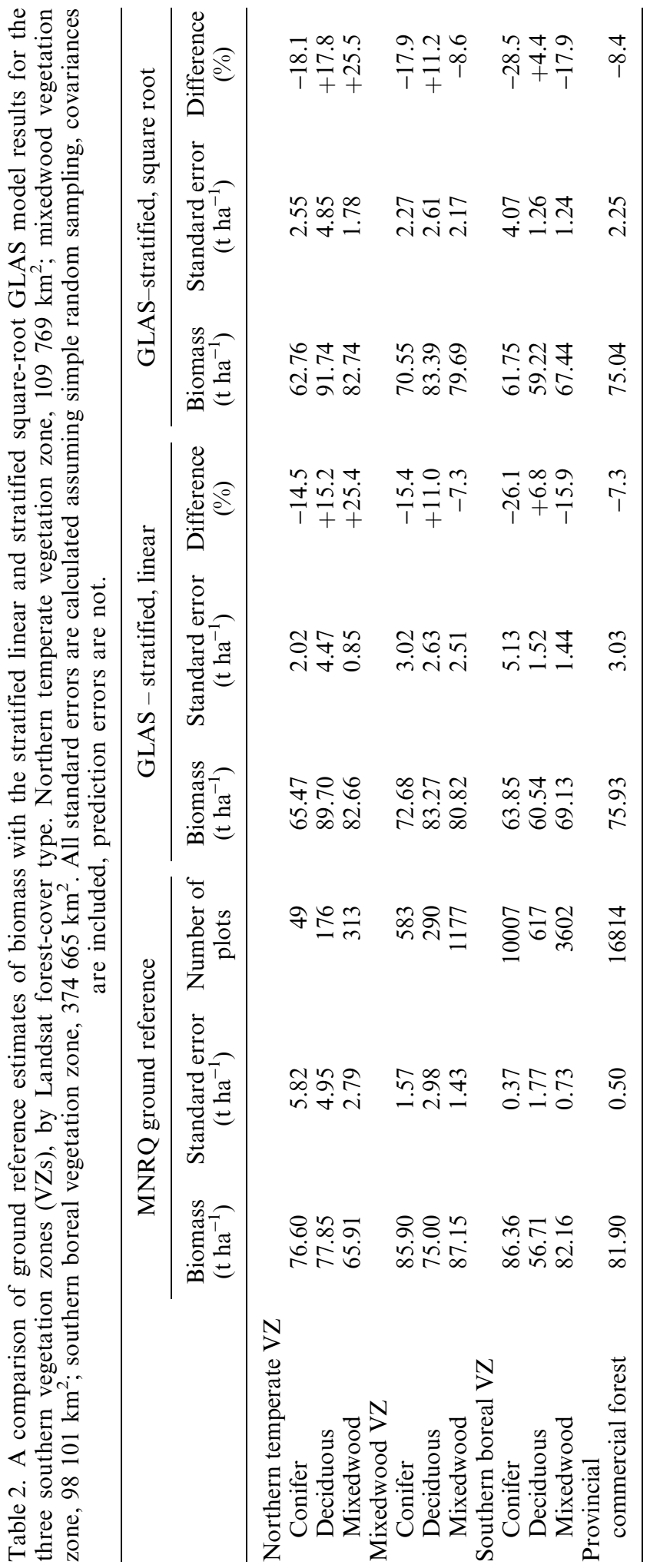


carbon credit of up to $2.64 \times 10^{9}$ euros for Québec, depending on which model was used at $t 1$ and which at $t 2$. The results in table 1 indicate that LiDAR-based biomass and carbon monitoring will require model consistency between measurement epochs or, alternatively, a post-processing statistical methodology that would equate current estimates with ones previously made using a different model or LiDAR sensor.

The accuracy and precision of the four models can be assessed, at least in the three southern vegetation zones, by comparing GLAS-based estimates to biomass estimates on the 16814 ground plots, accumulated across Landsat vegetation classes (table 2). All four models underestimated ground-based southern provincial estimates by amounts ranging from -7.3 to $-12.4 \%$. Models (2) and (4), the stratified linear and stratified square-root models, were, respectively, the most accurate and most precise at the regional level. The ground reference information and the stratified GLAS model results are reported in table 2 , by forest-cover type within vegetation zone and for the entire southern portion of the Province. This result argues for using optical imagery, e.g. Landsat, to identify those land-cover types capable of supporting forest biomass and using the GLAS measurements to estimate biomass only in forested cover types.

\subsection{GLAS height and biomass retrievals, by latitude}

The first evidence that the GLAS waveform LiDAR may not be able to measure short-stature forest is illustrated in figure 1. A total of 272 GLAS pulses measured by the airborne profiling LiDAR were quality-assessed for Landsat ETM+ cover-type homogeneity, low SRTM slopes and lack of GLAS signal saturation. Figure 1 illustrates the expected decrease in average forest height as measured by the airborne and space LiDARs, with increasing latitude. The airborne profiler measures the average height of all pulses acquired on a given GLAS pulse. The GLAS height reports the vertical location of that portion of the waveform above the ground peak, where $50 \%$ of the waveform energy lies above the height and 50\% below. The northern tree line in Québec varies from approximately $56^{\circ} \mathrm{N}$ in western Québec on the Hudson Bay, to

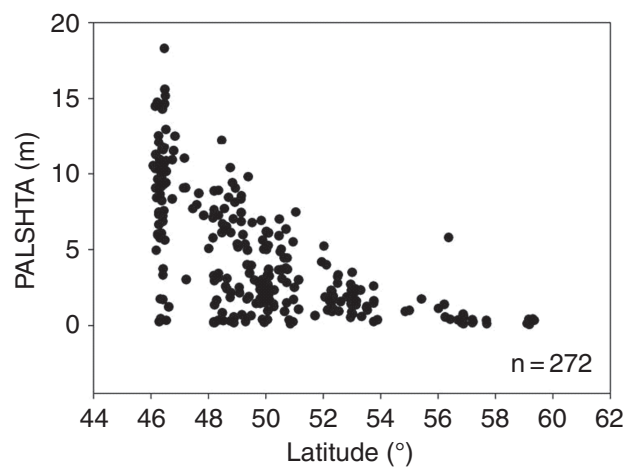

(a)

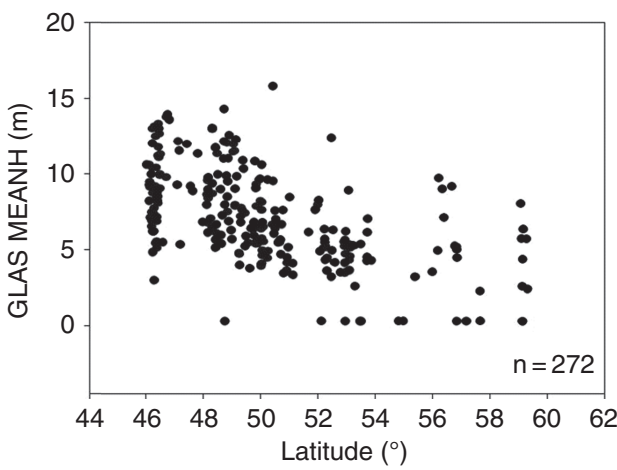

(b)

Figure 1. Scatter plots of airborne and space LiDAR estimates of canopy height: $(a)$ airborne laser profiling average height (PALS HTA) versus north latitude and (b) GLAS mean canopy height (GLAS MEANH, 50\% waveform energy level to ground peak) versus north latitude for 272 GLAS pulses in Québec. The 272 areas measured by the airborne laser and by GLAS are coincident. 
$\sim 58^{\circ}-59^{\circ} \mathrm{N}$ across central and eastern Québec. On northerly plots near or at the tree line, where the profiling LiDAR was essentially measuring zero heights, GLAS was recording tree heights of up to $8 \mathrm{~m}$.

Figure 2 further quantifies this decorrelation and illustrates two relationships that quantitatively describe the capability of the ICESat I / GLAS LiDAR to: (1) estimate biomass and (2) measure height in northern temperate and boreal forests. The reader can use her/his own subjective judgment in conjunction with the $R^{2}$ values plotted in figure 2 to determine at what point GLAS height and biomass retrievals fall below an 'acceptable' level. The figure and numbers unambiguously demonstrate that GLAS height retrievals deteriorate markedly as average canopy height decreases. GLAS versus airborne laser

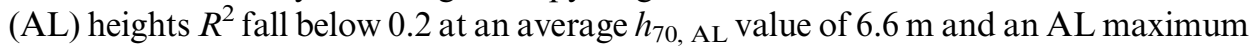
height value (average of three largest heights) of $11.9 \mathrm{~m}$. The corresponding GLAS values are $h_{75, \text { GLAS }}=6.2 \mathrm{~m}$ and $h_{14, \text { GLAS }}=17.5 \mathrm{~m}$. At $h_{70, \mathrm{AL}}$ and AL maximum heights values of $1.3 \mathrm{~m}$ and $6.8 \mathrm{~m}$ respectively, the ability of GLAS waveforms to measure or infer airborne measurements of canopy height essentially falls to zero. In north central Québec, this occurs at $\sim 53^{\circ} \mathrm{N}$, immediately north of the commercial-non-commercial forest boundary delineated by the Québec Ministry of Natural Resources.

Biomass retrievals are similarly limited. The ability of GLAS and SRTM to predict airborne LiDAR estimates of biomass generally decrease with increasing latitude. $R^{2}$ values fall below 0.2 when biomass values fall below $20 \mathrm{t} \mathrm{ha}^{-1}$; however, we note the weak biomass relationships in southern zones between $47^{\circ} \mathrm{N}$ and $52^{\circ} \mathrm{N}$, corresponding to zonal biomass averages of $30-90 \mathrm{t} \mathrm{ha}^{-1}$.

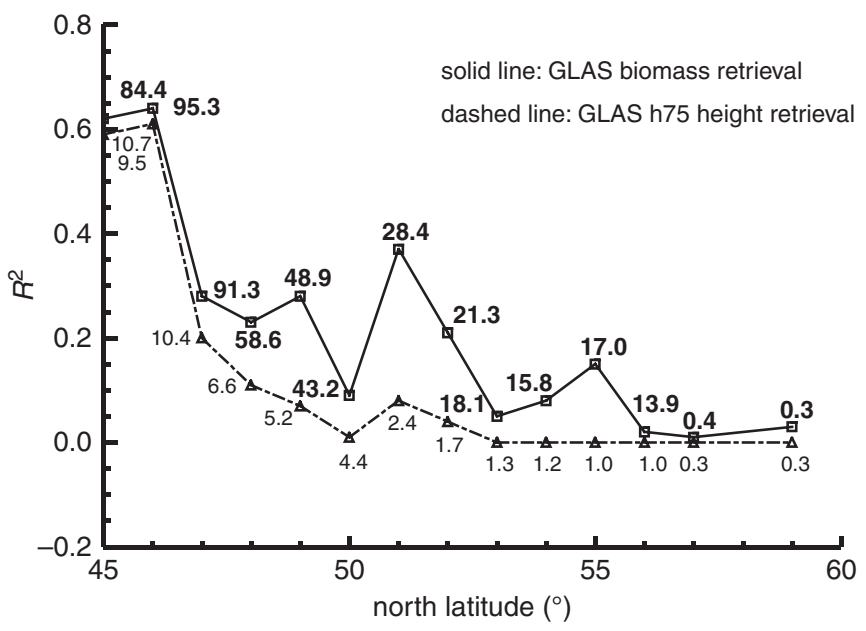

Figure 2. Coefficient of variation $\left(R^{2}\right)$ as a function of latitude in Québec for two linear relationships. Solid line: GLAS-SRTM estimates of biomass (model 1) compared with biomass estimates from PALS. Bold numbers show average PALS estimates of total aboveground dry biomass $\left(\mathrm{t} \mathrm{ha}^{-1}\right)$ in $1^{\circ}$ latitude increments. Dashed line: GLAS 75 th percentile heights as a function of airborne profiling LiDAR estimates of 70th percentile heights. Non-bold numbers report average airborne profiling LiDAR estimates of the 70th percentile heights in $1^{\circ}$ latitude increments. Number of GLAS pulses with coincident airborne profiling LiDAR measurements, by latitude zone, south to north: $n=429,607,609,995,818,480,477,676,585,134,136,146$, 68,66 (total $=6226$ pulses). The $y$-axis is extended to -0.2 to facilitate labelling. 
The results, perhaps, paint a bleaker picture of GLAS measurement capabilities than may actually be the case when sources of error are considered. The primary sources of error in this analysis are as follows:

- Airborne laser estimates of height are based on a laser profile across the GLAS footprint. Much of the GLAS footprint was not measured by the airborne profiler (see figures 2 and 4 in Boudreau et al. (2008)). That said, airborne profiles across GLAS footprints are repeatable. Sixty-five GLAS footprints were overflown twice during the 2005 airborne campaign. Comparison of airborne laser measurements of quadratic mean height $\left(h_{\mathrm{qa}}\right)$, overpass 1 versus overpass 2 , resulted in an equation of the following form: $h_{\mathrm{qa}}$, overpass $1=0.46+0.86_{\mathrm{qa}}$, overpass $2 ; R^{2}=0.74$, $\mathrm{RMSE}=2.1 \mathrm{~m}$, with heights measured in metres.

- The L2a GLAS footprint is an ellipse with major and minor axes of approximately $110 \times 70 \mathrm{~m}$, with the major axis canted $\sim 45^{\circ}$ to the direction of the GLAS orbit and the laser aircraft's flight track. Airborne LiDAR measurements were extracted for a $65 \mathrm{~m}$ profile coincident with the GLAS footprint in the direction of the orbit, not in the direction of the major axis of the footprint.

- Airborne laser estimates of biomass, which serve as ground reference in this analysis, are themselves inherently noisy (see figure 5 in Boudreau et al. (2008)). For instance, the non-stratified AL biomass equation has an $R^{2}=0.65$ and an $\mathrm{RMSE}=25.5 \mathrm{t} \mathrm{ha}^{-1}$. In other words, the ground reference biomass values are estimates, not 'truth'.

- Both the airborne profiling LiDAR and the GLAS LiDAR shots contain geolocation error. Both are of the order of $15 \mathrm{~m}$ (1 standard deviation).

Nevertheless, these results are of particular concern because they illustrate the current limitations of the ICESat / GLAS waveforms that measure the response of forest to 6 ns pulses. Even with ambiguities introduced by the sources of error listed above, the results indicate that short, open boreal forests near the tree line are not adequately measured by the GLAS LiDAR onboard ICESat I. The importance of space LiDAR altimetry for measuring and monitoring boreal forest structure in remote, inaccessible areas where climate change will be most rapid cannot be overstated. Scientists currently designing the ICESat II / GLAS LiDAR are contemplating a GLAS instrument with a 50-70 m circular footprint and a $10 \mathrm{~ns}$ pulse width. They prefer the longer pulse duration so that they can increase pulse power to help 'punch through' clouds and fog that commonly plague the coastal margins of major ice sheets such as Greenland, areas that are currently quite dynamic. However, such an increase may further exacerbate the capability of GLAS to monitor high-latitude forests by effectively 'smearing' structures in the waveform that allow us to retrieve canopy height. It is an open question and further research is needed, quickly, to quantify trade-offs between pulse width and forest height retrievals, with particular attention paid to short-stature, open forest.

\section{Discussion}

Within the next decade, the forestry LiDAR community can expect to have access to extensive datasets that will enable us to conduct regional and national assessments from space. Researchers have already demonstrated that, even with GLAS optimized for ice rather than vegetation measurements, analysts can develop comprehensive, extensive, timely estimates of forest biomass and carbon on areas encompassing hundreds of thousands to well over a million square kilometres. The use of space- 
based laser altimetry, specifically GLAS waveform data, currently presents numerous challenges, e.g. large footprints that convolve forest-canopy structure with topography in the presence of slope, an apparent insensitivity to small, sparse woodland heights, significant laser power changes over time (Abshire et al. 2005), data collection epochs (late autumn, early spring) tailored to ice studies but which are non-optimal from a vegetation measurement/monitoring standpoint, changing footprint shapes and orientations and non-contiguous profiles. The space LiDARs currently under design may mitigate some of these problems.

However, concerning GLAS, outstanding issues remain. These issues include: (1) an inability to adequately deconvolve the topographic and forest-canopy signals in large-footprint waveform data based solely on waveform attributes, although Lefsky et al. (2007) have taken steps to mitigate this problem; (2) a temporal hole in GLAS vegetation measurements between October 2008 and ca. 2017; (3) a reduced capability to measure heights accurately in sparse boreal forests with maximum heights of the order of $11.9 \mathrm{~m}$ and an essentially complete loss of height information in sparse boreal forests with maximum heights of $6.8 \mathrm{~m}$ or less; and (4) the significant technological differences between ICES at I and II that will completely change how forest structure is measured.

Monitoring changes to above-ground biomass and carbon stocks over time using airborne or space LiDARs raises its own set of issues, issues that will come to the forefront and call into question the validity of those laser-based estimates if we do not address them proactively. If LiDAR surveys at $t 1$ and $t 2$ are to be compared to assess, for instance, compliance with carbon agreements or to provide the quantitative estimates needed to purchase or sell carbon credits, then those $t 1$ and $t 2$ surveys must be consistent. Consistency in this context involves the use of:

- the same ground-based allometry at $t 1$ and $t 2$;

- the same statistical framework, e.g., design, sample size, number of phases;

- the same predictive models; and

- the same sensor, or a different sensor with the same flight configuration with respect to laser power, repetition rate, footprint size and pulse width.

The good news is that many of these factors are in our control: the allometry, the statistical framework and the model selection. Furthermore, if an analyst wants to update the allometry or improve/change predictive models, this can be done and the old $t 1$ data reprocessed with the improved versions to ensure comparability. What is most likely not in our control is the sensor, i.e. the operational characteristics of the airborne or space LiDAR. Airborne LiDAR technology is changing so rapidly that commercial data providers commonly swap out their 1 or 2 year old scanners for newer, faster, improved versions. In addition, the satellite LiDARs discussed in this paper typically have design lives of 3-5 years. We can be fairly certain that most regional surveys carried out every 5 to 10 years will be done with different sensors.

\section{Conclusions}

The results presented in this paper provide one example of the effects of allowing one item on the consistency checklist to stray. Provincial estimates changed $\sim 7 \%$ due only to changes in model form and due to changes to the rules used to process the GLAS data. The forestry LiDAR community should begin to address questions concerning consistency and calibration in order to develop procedural or statistical techniques to 
ensure comparability of LiDAR-based surveys carried out years apart. These results provide an impetus to develop statistical procedures that can effectively draw equivalence between multi-temporal, regional LiDAR-based biomass or carbon estimates that might not be directly comparable due, perhaps, to the use of different predictive models, different allometry, or changing LiDAR sensors in different measurement periods.

The ICESat / GLAS satellite, collecting well over $1 \times 10^{9}$ waveform measurements over a 6 year period, has provided a rich dataset with respect to characterizing forest structure globally. However, the results of this study indicate that the utility of these waveform measurements with respect to accurately characterizing forest structure may be greatest in tall, dense forests, e.g. the tropical and temperate forests, and least in short-stature, sparse forests, such as those found near topographic and climatic tree lines. It follows that estimates of above-ground carbon and biomass derived from these measurements, such as those reported by Nelson et al. (2009b), should be viewed with greater scepticism as one moves into the taiga and treed tundra vegetation zones. Investigators may wish to consider alternate remote-sensing assets that perform well in low-biomass situations, e.g. cross-polarized (HV) X, C and/or L-band space radars, in order to estimate biomass and carbon in these northern ecotones.

\section{References}

Abshire, J.B., Sun, X., Riris, H., Sirota, J., McGarry, J., Palm, S., Yi, D. and Liiva, P., 2005, Geoscience Laser Altimeter System (GLAS) on the ICESat mission: on-orbit measurement performance. Geophysical Research Letters, 32, p. L21S02.

Botkin, D.B. and Simpson, L.G., 1990, Biomass of the North America boreal forest: a step toward accurate global measures. Biogeochemistry, 9, pp. 161-174.

Boudewyn, P., Song, X., Magnussen, S. and Giluis, M.D., 2007, Model-based, Volume to Biomass Conversion for Forested and Vegetated Land in Canada. Info. Report BC-X-411, Natural Resources Canada, Canadian Forest Service, Pacific Forestry Centre, Victoria BC.

Boudreau, J.B., Nelson, R., Margolis, H., Beaudoin, A. and Guindon, L., 2008, An analysis of regional aboveground forest biomass using airborne and spaceborne lidar in Québec. Remote Sensing of Environment, 112, pp. 3876-3890.

Gower, S.T., Vogel, J.G., Norman, J.M., Kucharik, C.J., Steele, S.J. and Stow, T.K., 1997, Carbon distribution and aboveground net primary production in aspen, jack pine and black spruce stands in Saskatchewan and Manitoba, Canada. Journal of Geophysical Research, 102, pp. 29029-29041.

Grasia, M.G. (Ed.), 1990, Forest Map of USSR, scale: 1:2 500000 (Moscow: Soyuzgiproleskhoz).

Gregoire, T.G., Lin, Q.F., Boudreau, J. and Nelson, R., 2008, Regression estimation following the square-root transformation of the response. Forest Science, 54, pp. 597-606.

Houghton, R.A., Skole, D.L., Nobre, C.A., Hackler, J.L., Lawrence, W.H. and Chomentowski, W.H., 2000, Annual fluxes of carbon from deforestation and regrowth in the Brazilian Amazon. Nature, 403, pp. 301-304.

Lambert, M.-C., UnG, C.-H. and Raulier, F., 2005, Canadian national tree aboveground biomass equations. Canadian Journal of Forest Research, 35, pp. 1996-2018.

Lefsky, M., Harding, D., Keller, M., Cohen, W.B., Carabajal, C.C., Espirito-Santo, F.D.B., Hunter, M.O. and Deoliveira, R., 2005, Estimates of forest canopy height and aboveground biomass using ICESat. Geophysical Research Letters, 32, p. L22S02.

Lefsky, M.A., Keller, M., Pang, Y., Decamargo, P.B.. and Hunter, M.O., 2007, Revised method for forest canopy height estimation from the geoscience laser altimeter system waveforms. Journal of Applied Remote Sensing, 1, p. 013537.

Ministère des Ressources Naturelles, de la Faune et des Parcs (MRNFPQ), 2003, Zones de Végétation et Domaines Bioclimatiques du Québec. Gouvernement du Québec, 
Ministère des Ressources naturelles, de la Faune et des Parcs, Direction des Inventaires Forestiers, Code de diffusion, 2003-3043.

Myers, R., 1989, Classical and Modern Regression with Applications, 2nd ed. (Boston, MA: PWS-Kent Publishing Co.)

National Research Council, 2007, Earth science and applications from space: national imperatives for the next decade and beyond, Executive summary (Washington, D.C.: National Academies Press). Available online at: http://www.nap.edu/catalog/11820.html (accessed 29 July 2008).

Nelson, R.F., Parker, G. and Hom, M., 2003, A portable airborne laser system for forest inventory. Photogrammetric Engineering and Remote Sensing, 69, pp. 267-273.

Nelson, R., Ranson, K.J., Sun, G., Kimes, D., Kharuk, V. and Montesano, P., 2009a, Siberian timber volume maps derived from MODIS and ICESat / GLAS data. Remote Sensing of Environment, 113, pp. 691-701.

Nelson, R., Boudreau, J., Gregoire, T.G., Margolis, H., Nesset, E., Gobakken, T. and STÅHL, G., 2009b, Estimating Québec Provincial forest resources using ICESat / GLAS. Canadian Journal of Forest Research, 39, pp. 862-881.

Ranson, K.J., Kimes, D., Sun, G., Nelson, R., Kharuk, V. and Montesano, P., 2007, Using MODIS and GLAS data to develop timber volume estimates in central Siberia. In IEEE IGARSS, 23-26 July 2007, Barcelona, Spain, pp. 2306-2309 (Piscataway, NJ: IEEE).

Rosette, J.A.B., North, P.R.J. and SuÁrez, J.C., 2008, Vegetation height estimates for a mixed temperate forest using satellite laser altimetry. International Journal of Remote Sensing, 29, pp. 1475-1493.

Shepashenko, D., Shvidenko, A. and Nilsson, S., 1998, Phytomass (live biomass) and carbon of Siberian forests. Biomass and Bioenergy, 14, pp. 21-31.

Sun, G., Ranson, K.J., Kimes, D.S., Blair, J.B. and Kovacs, K., 2008, Forest vertical structure from GLAS: an evaluation using LVIS and SRTM data. Remote Sensing of Environment, 112, pp. 107-117.

Wulder, M.A., Dechka, J.A., Gillis, M.A., Luther, J.E., Hall, R.J., Beaudoin, A., and FrankLIN, S.E., 2003, Operational mapping of the land cover of the forested area of Canada with Landsat data: EOSD land cover program. The Forestry Chronicle, 79, pp. 1075-1083. 